\title{
PENGARUH PELATIHAN KADER KESEHATAN JIWA TERHADAP PERSEPSI KADER DALAM MERAWAT ORANG DENGAN GANGGUAN JIWA
}

\author{
Putu Ari Indrawati ${ }^{1}$, Ni Made Dian Sulistiowati ${ }^{2}$, Putu Oka Yuli Nurhesti ${ }^{1}$ \\ ${ }^{1}$ Program Studi Ilmu Keperawatan Fakultas Kedokteran Universitas Udayana \\ ${ }^{2}$ Departemen Keperawatan Jiwa, Program Studi Ilmu Keperawatan, Fakultas Kedokteran, Universitas Udayana \\ sulistiowati.md@unud.ac.id
}

\begin{abstract}
ABSTRAK
Gangguan jiwa adalah suatu penyimpangan proses pikir, alam perasaan, dan prilaku seseorang, yang disebabkan oleh gangguan pada fungsi sosial, psikologis, genetik, fisik/kimiawi, atau biologis. Salah satu metode yang dapat digunakan dalam merawat orang dengan gangguan jiwa adalah pemberian psikofarmaka dan penanganan secara psikologis yang dilakukan oleh tenaga kesehatan, keluarga, dan masyarakat. Saat ini masih terdapat stigma psikiatri negatif di masyarakat, oleh karena itu hal yang harus dibenahi adalah persepsi yang salah mengenai gangguan jiwa tersebut. Salah satu cara yang dapat dilakukan dengan membentuk kader kesehatan jiwa yang secara sukarela mau berpartisipasi dalam manajemen kasus gangguan jiwa yang ada di masyarakat. Kader merupakan bentuk pemberdayaan masyarakat sehingga masyarakat mulai secara swadaya melakukan pencegahan terkait masalah kesehatan. Tujuan penelitian ini adalah untuk mengetahui pengaruh pelatihan kader kesehatan jiwa terhadap persepsi kader dalam merawat orang dengan gangguan jiwa. Penelitian ini merupakan penelitian kuantitatif jenis quasy experiment, dan merupakan studi komparatif, dengan design penelitian pre post-test design. Sampel dalam penelitian ini berjumlah 27 orang didapat dari teknik sampling purposive sampling. Hasil penelitian berdasarkan uji statistik didapatkan nilai $\mathrm{z}=-4,568$, dengan $\mathrm{p}$ value $=0,000,(\mathrm{p}<\alpha$ $(0,05))$, dengan demikian didapat hasil pelatihan kader kesehatan jiwa berpengaruh terhadap persepsi kader dalam merawat orang dengan gangguan jiwa.
\end{abstract}

Kata kunci: Pelatihan kader, Persepsi kader, Merawat Orang Dengan Gangguan Jiwa.

\section{ANALYZE THE INFLUENCE OF CADRE FOR MENTAL ILLNESS TRAINING ON CADRE PERCEPTION FOR CARING PEOPLE WITH MENTAL ILLNESS}

\begin{abstract}
Mental illness is an abnormality of thinking, emotion, and behavior process which is caused by social, psychological, genetics, phisical, or biological function disorders. Drug-induced could change in mood, thinking, and behavior process. Psychological treatments are kind of methods which can be used to treat someone who has experienced mental illness. It can be done by health worker, family, and society. Negative psychyatry stigma still goes wide nowadays and this wrong perception related to mental illness should be cleared. One way that we can do is to create cadre for mental illness. The cadre is voluntarily participated for managing mental illness cases on society. Cadre is one of society empowerments so that expected the society begin to prevent health problems by self-supporting. This study aims to analyze the influence of cadre for mental illness training on cadre perception for caring people with mental illness. This study was a comparative study with quantitative approach. This study was quasi experiment with pre and post test design. There were 27 samples that collected by porposive sampling technique. The results of this study based on statistic test were obtained value of $z=-4,568$, with $p$ value $=0,000,(p<\alpha(0,05))$. Based on the above findings, it can be concluded that there are significant impact of cadre mental illness training on cadre perception for caring.
\end{abstract}

Keywords: Cadre training, Cadre perception, Mental illness care.

\section{PENDAHULUAN}

Kesehatan jiwa adalah suatu kondisi dimana seorang individu dapat berkembang secara fisik, mental, spiritual, dan sosial, sehingga individu tersebut menyadari kemampuan sendiri, dapat mengatasi tekanan, dapat bekerja secara produktif, dan mampu memberikan kontribusi untuk komunitasnya (Undang-Undang Republik Indonesia Nomor 18 Tahun 2014 Tentang Kesehatan Jiwa, 2014). Tidak berkembangnya koping individu dengan baik dapat menyebabkan terjadinya gangguan jiwa 
(Sulistiowati, 2015). Menurut Keliat, Akemat, Daulima, \& Nurhaeni (2013) gangguan jiwa yaitu suatu perubahan yang menyebabkan adanya gangguan pada fungsi jiwa, yang menimbulkan penderitaan pada individu atau hambatan dalam melaksanakan peran sosial.

Orang Dengan Gangguan Jiwa (ODGJ) adalah orang yang mengalami gangguan dalam pikiran, prilaku, dan perasaan yang termanifestasi dalam bentuk sekumpulan gejala dan atau perubahan prilaku yang bermakna, serta dapat menimbulkan penderitaan dan hambatan dalam menjalankan fungsi orang sebagai manusia (Undang-Undang Republik Indonesia Nomor 18 Tahun 2014 Tentang Kesehatan Jiwa, 2014). Gangguan jiwa dibagi menjadi gangguan jiwa berat dan gangguan mental emosional (Riset Kesehatan Dasar, 2013). Data statistik WHO dalam Hawari (2009), menyebutkan jumlah dari penderita gangguan jiwa di dunia pada tahun 2001 mencapai 450 juta jiwa. Berdasarkan data Riset Kesehatan Dasar (2013) sebanyak 1.728 orang Indonesia mengalami gangguan jiwa berat dengan prevalensi gangguan jiwa berat adalah 1,7 per mil. Gangguan jiwa berat terbanyak ke-5 terdapat di Bali. Berdasarkan data BPS, Bali memiliki luas wilayah 5.636,66 km2 dan jumlah penduduk sebesar 3.890 .757 orang. Gangguan jiwa di Bali berdasarkan laporan data kesakitan jiwa Dinas Kesehatan Provinsi Bali tahun 2014 total jumlah gangguan jiwa yaitu 8248 jiwa (Dinkes. Prov. Bali, 2014).

Berdasarkan studi pendahuluan yang dilakukan di Dinas Kesehatan Kota Denpasar tahun 2015 menyatakan terdapat 740.602 jiwa penduduk di kota Denpasar. Terdapat 252 orang dengan gangguan jiwa yang datang berobat ke Puskesmas. Angka tertinggi terdapat pada wilayah kerja Puskesmas II Dentim dengan total jumlah penduduk 62.255 orang terdapat 59 $(41,2 \%)$ ODGJ yang datang dan tercatat di Puskesmas. Sedangkan apabila menurut data Riskesdas 2013 dimana jumlah gangguan jiwa berat Provinsi Bali sebanyak 2,3\% permil, antara jumlah penduduk dan jumlah ODGJ tersebut didapat estimasi ODGJ di wilayah Puskesmas II Dentim sebanyak 143 orang. Sehingga terdapat selisih $84(58,8 \%)$ ODGJ di wilayah Puskesmas II Dentim belum ditemukan.

Disamping itu dewasa ini banyak persepsi yang salah atau mitos yang terkait mengenai gangguan jiwa, adanya stigma psikiatri di Indonesia beranggapan bahwa gangguan jiwa disebabkan oleh pengaruh jahat, roh halus, lemah iman dan guna-guna sehingga menyebabkan pasien dibawa berobat ke dukun dan paranormal, hal ini dipengaruhi karena kurangnya tingkat pengetahuan masyarakat mengenai gangguan jiwa (Keliat, Panjaitan, \& Daulima, 2006). Berdasarkan hal tersebut maka diperlukan strategi khusus untuk mengatasi serta mencegah terjadinya gangguan kesehatan jiwa masyarakat. Adapun upaya pencegahan gangguan kesehatan jiwa ada tiga, yaitu pencegahan primer, sekunder, dan tersier (Keliat, Daulima, \& Farida, 2011). Menurut studi pendahuluan yang dilakukan oleh Marchira (2011) bagi negara berkembang seperti Indonesia dengan sumber daya kesehatan jiwa yang terbatas, hal yang paling realistis adalah mengintegrasikan pelayanan kesehatan jiwa di pelayanan primer, contohnya puskesmas. Salah satu upaya dalam pencegahan primer tersebut adalah pembentukan kader kesehatan jiwa.

Dengan adanya kader kesehatan jiwa, maka masyarakat akan lebih terpapar mengenai kesehatan jiwa yang nantinya akan mempermudah proses penemuan kasus baru di masyarakat. Lebih jauh, ke depan kader kesehatan jiwa yang dibentuk itu akan berperan sebagai support system di masyarakat (Pramujiwati, Anna Keliat, \& Ice Yulia Wardani, 2013). Kader kesehatan jiwa mampu melaksanakan hal yang sederhana seperti, deteksi dini kasus gangguan jiwa, penggerakan keluarga sehat, resiko, dan sakit untuk ikut penyuluhan kesehatan jiwa, penggerakan ODGJ untuk ikut rehabilitasi dan TAK, serta kunjungan rumah untuk pasien yang mandiri (Keliat, Panjaitan, \& Riasmini, 2010). Oleh karena itulah kader kesehatan perlu dilatih dalam meningkatkan kemampuan kader agar dapat mengelola dan menjalankan pelayanan kesehatan khususnya dalam menyampaikan informasi dan pendidikan kesehatan secara langsung kepada masyarakat sekitar.

Saat ini Bali belum memiliki kader kesehatan jiwa sehingga kasus angka kejadian gangguan jiwa dimasyarakat khususnya wilayah Denpasar masih belum banyak ditemukan. Oleh karena itu peneliti menganggap metode penyelenggaraan pelatihan kader kesehatan jiwa ini dianggap potensial penting untuk mengatasi masalah yang ada dan juga untuk mengetahui pengaruh pelatihan kader kesehatan jiwa terhadap persepsi kader dalam merawat orang dengan gangguan jiwa. 


\section{METODE}

Penelitian ini merupakan penelitian kuantitatif jenis quasy experiment, dan merupakan studi komparatif. Metode yang digunakan pada penelitian ini adalah pre post test design untuk mengetahui pengaruh pelatihan kader kesehatan jiwa terhadap persepsi kader dalam merawat orang dengan gangguan jiwa. Populasi dari penelitian ini adalah kader kesehatan (posyandu, jumantik) yang dipilih menjadi kader kesehatan jiwa di wilayah kerja Puskesmas II Dentim Kota Denpasar Provinsi Bali, dengan jumlah sampel sebanyak 27 kader. Pengambilan sampel dengan menggunakan teknik non probability sampling jenis purposive sampling. Adapun kriteria sampel adalah merupakan kader kesehatan yang bersedia menjadi kader kesehatan jiwa, mengikuti pelatihan dari awal sampai akhir, peran aktif selama menjadi kader kesehatan. Kegiatan penelitian mulai dari perijinan sampai dengan pengambilan data dilakukan dari bulan September sampai Desember 2015.

Pengumpulan data dilakukan dengan menggunakan kuisioner data demografi dan kuisioner persepsi tentang merawat orang dengan gangguan jiwa. Kuisioner telah diuji ketepatannya oleh Maunyana Astusti (2012) yang telah dimodifikasi dan diuji ketepatannya kembali oleh Yuliastini (2015) yang terdiri dari 23 pertanyaan mengenai penyebab gangguan jiwa, gejala gangguan jiwa, beratnya gangguan jiwa, resiko gangguan jiwa, pencegahan gangguan jiwa, dan merawat orang dengan gangguan jiwa dirumah. Saat pengumpulan data, peneliti dibantu oleh perawat spesialis jiwa dan perawat CMHN dipuskesmas II Denpasar Timur dalam memberikan pelatihan. Setelah menentukan responden maka peneliti menjelaskan tujuan kegiatan dan meminta persetujuan keikutsertaan dalam kegiatan. Responden yang berjumlah 27 orang kemudian dikumpulkan untuk dilakukan pelatihan. Sebelum memulai pelatihan, peneliti memberi pretest dengan alat ukur berupa kuisioner dan menjelaskan cara pengisiannya serta dilakukan fasilitasi terhadap kemungkinan kebingungan atau kesalahan dalam mengisi kuesioner. Semakin tinggi jumlah skor maka persepsi semakin tinggi, rentang skor tertinggi adalah 23 dan terendah adalah 0 .

Kemudian kader diberikan pelatihan dalam waktu 2 hari dengan total waktu 10 jam oleh pembicara dan didampingi oleh peneliti. Untuk menunjang keberhasilan pelatihan kader, sebelum dilaksanakan pelatihan peneliti telah mempersiapkan materi yang dibutuhkan, sarana prasarana yang dibutuhkan, metode pelatihan yang digunakan yaitu ceramah interaktif, diskusi kelompok, demonstrasi, simulasi bermain peran, studi kasus, dan praktik kunjungan rumah. Setelah pelatihan kader selesai, peneliti kembali memberikan post test. Sebelum dilakukan pengujian statistik dilakukan uji normalitas data terhadap data sebelum dan sesudah diberikan pelatihan kader Keswa dengan tingkat kepercayaan 95\% dan $\alpha=0,05$. Dilihat menggunakan uji Shapiro Wilk karena jumlah sampel kurang dari 50 orang. Didapatkan hasil data tidak berdistribusi normal ( $\mathrm{p}$ value < 0,05) maka dilakukan uji non parametrik dengan uji wilcoxon.

\section{HASIL}

Pada tabel 1 diperlihatkan data bahwa rata-rata persepsi kader kesehatan jiwa sebelum diberikan pelatihan kader berada pada kategori baik yaitu 16,96. Skor minimum persepsi kader sebelum pelatihan adalah 15 dan skor tertinggi adalah 21 (rentang skor 0-23). Sedangkan ratarata persepsi kader setelah diberikan pelatihan kader kesehatan jiwa berada pada kategori sangat baik yaitu 21,30. Skor minimum persepsi kader setelah pelatihan adalah 20 dan skor tertinggi adalah 22 (rentang skor 0-23).

Hasil penelitian berdasarkan uji statistik dengan Wilcoxon test didapatkan pada tabel 2 nilai $\mathrm{z}=$ 4,568 , dengan $\mathrm{p}$ value $<0.05$ (0.000). Dengan demikian didapat hasil pelatihan kader kesehatan jiwa berpengaruh terhadap persepsi kader dalam merawat orang dengan gangguan jiwa.

Tabel 1.

Nilai rata-rata persepsi kader sebelum dan sesudah dilakukan pelatihan kader kesehatan jiwa $(n=27)$

\begin{tabular}{lcccc}
\hline \multicolumn{1}{c}{ Variabel } & Mean & Median & Standar Deviasi & Min-Max \\
\hline Persepsi kader sebelum pelatihan & 16,96 & 17,00 & 1,720 & $15-21$ \\
\hline Persepsi kader sesudah pelatihan & 21,30 & 21,00 & 0,669 & $20-22$ \\
\hline
\end{tabular}




\section{Tabel 2}

Analisis pengaruh pelatihan kader kesehatan jiwa terhadap persepsi kader dalam merawat orang dengan gangguan jiwa $(n=27)$

\begin{tabular}{llccc}
\hline & Variabel & Negative-positive Ranks & Z & P value \\
\hline $\begin{array}{l}\text { Persepsi kader sebelum dan } \\
\text { kader kesehatan jiwa }\end{array}$ & setelah pelatihan & $0-27$ & 4,568 & 0,000 \\
\hline
\end{tabular}

\section{PEMBAHASAN}

Rata rata persepsi kader sebelum diberikan pelatihan kader kesehatan jiwa adalah 16,96 (kategori baik dalam rentang skor 0-23). Persepsi dengan skor 16 berjumlah 6 orang dengan persentase $22,2 \%$, skor 17 berjumlah 8 orang dengan persentase $29,6 \%$, skor 18 berjumlah 1 orang dengan persentase $3,7 \%$, skor 19 berumlah orang dengan persentase $11,1 \%$, skor 20 berjumlah 2 orang dengan persentase $7,4 \%$, dan skor 21 berjumlah 1 orang dengan persentase $3,7 \%$. Berdasarkan hasil analisis terhadap masing-masing item pertanyaan kuisioner, sebelum diberikan pelatihan menunjukkan bahwa pada aspek penyebab gangguan jiwa, sebanyak 14 dari 27 responden atau sekitar $52 \%$ responden menjawab salah pada item pertanyaan nomor 1 yaitu responden beranggapan bahwa gangguan jiwa disebabkan oleh roh jahat atau kutukan leluhur. Pada item soal nomor 9 dan 10 mengenai beratnya penyakit gangguan jiwa, sebagian besar responden menjawab gangguan jiwa hanya disebabkan oleh keturunan dan merupakan penyakit yang tidak dapat disembuhkan. Demikian juga pada item soal nomor 11, sebanyak 25 responden atau sekitar 93\% masih beranggapan bahwa masyarakat yang menderita gangguan jiwa yang sudah parah harus dikurung/diisolasi karena sangat membahayakan. Sebanyak 24 responden atau sekitar $89 \%$ berpendapat bahwa penderita gangguan jiwa dapat disembuhkan dengan pengobatan tradisional.

Sesuai dengan teori yang disebutkan oleh Keliat et al., (2006) dalam masyarakat Indonesia, ada beberapa keadaan yang merupakan bentuk persepsi untuk individu dengan gangguan jiwa pertama, keyakinan atau kepercayaan bahwa gangguan jiwa itu disebabkan oleh guna-guna, tempat keramat, roh jahat, setan, sesaji yang salah, kutukan, banyak dosa, pusaka yang keramat, dan kekuatan gaib atau supranatural. Kedua, keyakinan atau kepercayaan bahwa gangguan jiwa merupakan penyakit yang tidak dapat disembuhkan. Ketiga, keyakinan atau kepercayaan bahwa gangguan jiwa merupakan penyakit yang bukan urusan medis. Keempat, keyakinan atau kepercayaan bahwa gangguan jiwa merupakan penyakit yang selalu diturunkan. Rata-rata persepsi kader setelah diberikan pelatihan kader kesehatan jiwa adalah 21,30 (kategori sangat baik). Persepsi kader setelah pelatihan dengan skor 20 berjumlah 3 orang dengan persentase $11,1 \%$, persepsi dengan skor 21 berjumlah 13 orang dengan persentase $48,1 \%$, serta persepsi dengan skor 21 berjumlah 11 orang dengan persentase $40,7 \%$.

Berdasarkan hasil analisis dari masing-masing item pertanyaan, terdapat skor lebih tinggi dari aspek yang lain, sebanyak 27 responden (100\%) menjawab benar pada soal nomor 110, yaitu pada aspek penyebab gangguan jiwa, gejala gangguan jiwa, dan beratnya penyakit gangguan jiwa. Dari hasil tersebut, dapat disimpulkan bahwa responden memiliki persepsi yang baik mengenai gangguan jiwa. Demikian juga seluruh responden (100\%) menjawab benar pada soal nomor 20-23, dapat disimpulkan bahwa persepsi responden sudah baik mengenai cara merawat orang dengan gangguan jiwa dirumah.

Penelitian Widagdo (2006) mengenai persepsi kader posyandu di Kecamatan Mlonggo Jawa Tengah, terhadap 124 orang kader menyatakan bahwa persepsi dan partisipasi kader mutlak membutuhkan motivasi, yang berupa supervisi ataupun reward kepada kader sehingga mampu mendorong kinerja kader dalam melaksanakan program posyandu. Motivasi tersebut dapat berasal dari lingkungan, yaitu pemerintah atau swasta, dan dapat juga berasal dari tokoh masyarakat sendiri. Hasil penelitian berdasarkan uji statistik didapatkan nilai $\mathrm{z}=$ 4,568 , dengan $\mathrm{p}$ value $=0,000,(\mathrm{p}<\alpha(0,05))$, dengan demikian didapat hasil hipotesis diterima. Oleh karena itu dapat disimpulkan bahwa pelatihan kader kesehatan jiwa bemanfaat dalam meningkatkan persepsi kader dalam merawat orang dengan gangguan jiwa di wilayah kerja Puskesmas II Denpasar Timur. 


\section{SIMPULAN DAN SARAN \\ Simpulan}

Berdasarkan hasil penelitian dapat disimpulkan sebagai berikut, persepsi kader sebelum pelatihan kader kesehatan jiwa menunjukkan kategori persepsi baik, persepsi kader setelah pelatihan kader kesehatan jiwa menunjukkan kategori persepsi sangat baik. Berdasarkan hasil uji analisis statistik dapat disimpulkan hipotesis diterima yaitu pelatihan kader kesehatan jiwa berpengaruh terhadap persepsi kader dalam merawat orang dengan gangguan jiwa.

\section{Saran}

Diharapkan kader dapat lebih memahami serta mengaplikasikan tugas dan fungsinya menjadi, memahami cara merawat orang dengan gangguan jiwa dirumah yang telah mandiri, dan mampu mempengaruhi masyarakat sekitar tentang pentingnya kesehatan jiwa dan dapat berdayanya orang dengan gangguan jiwa jika mendapatkan perawatan yang baik sehingga stigma buruk yang berkembang dimasyarakat dapat dihilangkan.

Diharapkan agar Dinas Kesehatan Kota Denpasar dan kabupaten lainnya yang ada di Propinsi Bali dapat membentuk kader kesehatan jiwa di setiap daerah wilayah puskesmas dan melaksanakan pelatihan kader kesehatan jiwa. Mengingat tugas dari kader kesehatan jiwa ini salah satunya juga untuk melakukan deteksi dini untuk kasus gangguan jiwa sehingga hal yang dapat memperburuk kondisi gangguan jiwa dapat dicegah, serta memberikan pelayanan yang menyeluruh kepada seluruh masyarakat.

Hasil penelitian ini diharapkan dapat dijadikan acuan/ data awal kepada peneliti lain yang ingin melakukan penelitian dengan ruang lingkup yang sama, dengan menambah responden atau ruang lingkup penelitian yang lebih luas atau melanjutkan penelitian yang dilakukan dengan cara memantau kinerja kader kesehatan jiwa yang telah dibentuk peneliti di wilayah kerja Puskesmas II Denpasar Timur.

\section{DAFTAR PUSTAKA}

Keliat, B. A., Akemat, Daulima, N. H., \& Nurhaeni, H. (2013). Keperawatan Kesehatan Jiwa Komunitas : CMHN (Basic Course). Jakarta: EGC.

Keliat, B. A., Daulima, N. H., \& Farida, P. (2011). Manajemen Keperawatan
Psikososial \& Kader Kesehatan Jiwa CMHN (Intermediate Course). Jakarta: EGC.

Keliat, B. A., Panjaitan, R. U., \& Daulima, N. H. (2006). Proses Keperawatan Kesehatan Jiwa (2nd ed.). Jakarta: EGC.

Keliat, B. A., Panjaitan, R. U., \& Riasmini, M. (2010). Manajemen Keperawatan Jiwa Komunitas Desa Siaga CMHN (Intermediate Course). Jakarta: EGC.

Pramujiwati, D., Anna Keliat, B., \& Ice Yulia Wardani, D. (2013). Pemberdayaan Keluarga Dan Kader Kesehatan Jiwa Dalam Penanganan Pasien Harga Diri Rendah Kronik Dengan Pendekatan Model Precede L. Green Di Rw 06, 07 Dan 10 Tanah Baru Bogor Utara. Jurnal Keperawatan Jiwa, 1(2), 170-177. https://doi.org/10.1175/JCLI-D-1400295.1

Riset Kesehatan Dasar. (2013). Jakarta.

Sulistiowati, N. M. D. (2015). Pengaruh Terapi Family Psychoeducation (FPE) Terhadap Kemampuan Keluarga Merawat Anggota Keluarga Dengan Gangguan Jiwa. COPING NERS (Community of Publishing in Nursing), 3(1), 1-7.

Undang-Undang Republik Indonesia Nomor 18 Tahun 2014 Tentang Kesehatan Jiwa. (2014).

Widagdo, L. (2006). Persepsi Kader Posyandu Di Kecamatan Mlonggo. Makara Kesehatan, 10(2), 54-59. Retrieved from http://repository.ui.ac.id/contents/koleks $\mathrm{i} / 2 / \mathrm{ee} 7 \mathrm{a} 4244 \mathrm{~b} 04009 \mathrm{c} 5621239 \mathrm{e} 948 \mathrm{c} 777$ 67d2f7507c.pdf

Yuliastini, P. (2015). Hubungan Persepsi Keluarga Tentang Skizofrenia dan Ekspresi Emosi Keluarga dengan Frekuensi Kekambuhan Skizofrenia di IRD RSJ Provinsi Bali. Universitas Udayana. 